This item was submitted to Loughborough's Research Repository by the author.

Items in Figshare are protected by copyright, with all rights reserved, unless otherwise indicated.

\title{
Luong test for the characterization of the shear post-cracking response of fiber reinforced concrete
}

PLEASE CITE THE PUBLISHED VERSION

https://doi.org/10.1016/j.conbuildmat.2017.05.135

\section{PUBLISHER}

(C) Elsevier

VERSION

AM (Accepted Manuscript)

\section{PUBLISHER STATEMENT}

This work is made available according to the conditions of the Creative Commons Attribution-NonCommercialNoDerivatives 4.0 International (CC BY-NC-ND 4.0) licence. Full details of this licence are available at: https://creativecommons.org/licenses/by-nc-nd/4.0/

\section{LICENCE}

CC BY-NC-ND 4.0

\section{REPOSITORY RECORD}

Blanco, Ana, C. Aire, Pablo Pujadas, and Sergio H. Cavalaro. 2019. "Luong Test for the Characterization of the Shear Post-cracking Response of Fiber Reinforced Concrete”. figshare. https://hdl.handle.net/2134/32295. 


\title{
Luong test for the characterization of the shear post-cracking response of fiber reinforced concrete
}

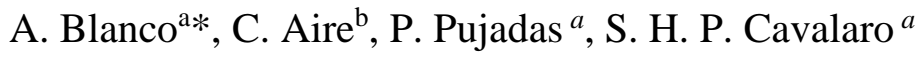 \\ ${ }^{a}$ Dept. of Civil and Environmental Engineering, Universitat Politècnica de Catalunya-BarcelonaTech, Jordi \\ Girona 1-3, Building C1-202, 08034 Barcelona, Spain. \\ b Ingeniería Estructural. Universidad Nacional Autónoma de México. Building 3-217. Circuito Escolar. \\ Ciudad Universitaria, 04510 Mexico City, Mexico. \\ * Corresponding author Tel.: +34-93-401-7825; fax: +34-93-401-1036; e-mail: ana.blanco@upc.edu
}

\begin{abstract}
The behavior of concrete subjected to shear can be significantly improved by the addition of fibers, which may partially or totally substitute the traditional steel stirrups (also known as links). Design recommendations include formulations to account for the contribution of the fibers. However, these formulations take the results of small-scale bending tests as input parameters. The main reason for that is the lack of standardized tests and the difficulty to assess direct shear in fiber reinforced concrete (FRC) both for the design and for the quality control. The present study proposes a test for the characterization of the post-cracking shear response of FRC. The test is validated through an experimental program with conventional concrete and FRC. The influence of different parameters (geometry of the specimen, the type and the content of fiber) is assessed and a comparison is made between the push-off test and the one proposed here. Results of an in-depth statistical analysis indicate that the latter is a simpler and valid alternative to evaluate the post-cracking shear response of FRC.
\end{abstract}

Keywords: shear, residual strength, FRC, Luong test, push-off test

\section{INTRODUCTION}

The inclusion of structural fibers in concrete not only enhances the tensile response but also the shear capacity of the composite material [1,2]. On one hand, fibers act as many small-sized, distributed reinforcing bars that bridge the crack and generate a restriction to shear displacement. On the other hand, fibers also limit the crack opening due to dilatancy, generating confining normal stresses that contribute to maintain the effect of aggregate interlock.

In view of the advantages of fiber reinforced concrete (FRC), several codes and recommendations have already proposed formulations to consider the contribution of the fibers in the design of elements subjected to shear. Interestingly, however, the parameter 
that accounts for such contribution depends solely on the residual tensile strength of the FRC obtained through a small-scale bending test [3-6].

Even though this test is convenient to derive the tensile constitutive curve for the design of FRC beams subjected to bending, its use for the shear design may be considered questionable. The stress distribution and the contribution of the fibers in a crack due to bending tend to differ considerably from the observed in a crack due to shear. Despite the link between the shear and the flexural behaviors, this might be a too rough approximation of reality with possible negative repercussion in terms of structural safety or optimization of material consumption. Likewise, the use of bending for the indirect quality control of the shear behavior is also questionable, especially in a material whose response is strongly dependent of fiber distribution.

The absence of standard and simple test method for the characterization and quality control of FRC is the main reason for this scenario. The complexity in terms of equipment, setup and execution of most shear tests would compromise the characterization in the context of a systematic quality control. The high crack displacement required to assess the shear behavior of FRC is another limiting issue since, as the displacement increases, the loading configuration changes and bending forces appear. This leads to a failure mechanism governed by a mix between shear and bending.

Considering the above, the main objective of the present study is to propose a simple and reliable test for the characterization of the post-cracking shear response of FRC. A brief literature review is conducted in order to identify the current approaches employed to evaluate shear in FRC. An adaptation of the Luong test [7] - originally conceived to evaluate shear in concrete and rocks - is made for the case of FRC. This test was selected due to its simplicity and its failure mechanism that may allow high displacements without increasing noticeably the bending moment.

In order to validate the suitability of Luong test, an experimental program with conventional concrete and FRC is performed. First, the failure mechanism and the results of the Luong test are compared to those of the push-off test. Then, a statistical analysis is performed to assess the influence of key parameters (such as the geometry of the specimen, the type and content of fibers) in the Luong test results.

The present study sheds light on the unresolved issue of the direct shear characterization of FRC by proposing a simple test that is experimentally validated and may serve for the direct characterization and quality control. Furthermore, the experimental data from several FRC mixes allows analyzing the influence of the type of fiber and its content on the residual shear response, thus increasing the knowledge currently available in the literature.

It is important to remark that the Luong test is not presented here as an alternative to the small-scale bending test but as a complementary method. Ideally, a Mode II fracture takes place in the Luong test, whereas a Mode I failure occurs in the bending test. 
Therefore, the cracking mechanism developed in each of them cannot be considered equivalent. Depending on the behavior of the structure, one test or the other will be more representative of the crack formation and evolution.

\section{SHEAR CHARACTERIZATION OF FRC}

The shear post-cracking behavior FRC may be evaluated through direct small-scale tests or tests on full-scale beams. The former allow assessing the in-plane shear failure and contribute to understanding the transfer of longitudinal shear, whereas the latter are normally used to evaluate failure in diagonal shear. Most of the recent studies from the literature have focused on the test of full-scale beams with or without transversal reinforcement [8-15]. In general, their results reveal a significant increase in the shear strength and ductility of the beams for fiber contents up to $1 \%$ by volume.

Characterization tests should be simple in execution, easily reproducible, applicable in practice and reliable, providing results that can be easily processed. Despite providing relevant information about the shear behavior of cracked FRC, the full-scale test does not fulfill all these requirements due to the high complexity, the high weight of the elements tested and the high costs. Therefore, it does not seem an adequate option for the systematic evaluation of the shear response of FRC.

The current trend is to move towards smaller and simpler tests. Push-off tests have been the most widely used small-scale alternative to evaluate the contribution of the fibers subjected to direct shear [8, 16-24].

Lee and Foster [21] performed push-off tests of specimens with steel fibers and measured the vertical (shear load direction) and horizontal displacements during the test. The results show that a vertical displacement of $2 \mathrm{~mm}$ induces a horizontal displacement over 0.5 $\mathrm{mm}$, revealing a certain rotation of the two parts of the cracked Z-shaped specimen that could induce bending forces. In order to reduce the incidence of the rotation in the loading configuration, a rigid steel frame may be placed at the mid-height of the specimen to restrain the horizontal crack opening. Even though such solution reduces changes in the loading configuration during the tests [23], it represents a drawback in terms of complexity. Moreover, the frame should be carefully designed to allow shear displacements of several $\mathrm{mm}$ without introducing significant forces against the shear movement.

\section{EXPERIMENTAL PROGRAM}

\subsection{Materials, concrete mix and basic properties}

Table 1 shows the information about the concrete compositions characterized in the experimental program. In total, 8 concrete mixes were cast: 1 without fibers (M0) and 7 with fibers (M1 to M7). CEM II was used with a water-to-cement ratio of 0.5. Waterreducing admixture was added to guarantee similar workability among all mixes. Sand with fineness modulus of 3.1 and two maximum aggregate sizes of $9.5 \mathrm{~mm}$ (mixes M0 to 
M6) and $12.7 \mathrm{~mm}$ (mix M7) were used. Notice that mix M7 presents a composition slightly different from the others due to variations implemented to assess the influence of the aggregate maximum size.

Table 1. Concrete composition

\begin{tabular}{|c|c|c|c|c|c|c|c|c|c|}
\hline \multirow{2}{*}{\multicolumn{2}{|c|}{ Component }} & \multicolumn{8}{|c|}{ Content } \\
\hline & & M0 & M1 & M2 & M3 & M4 & M5 & M6 & M7 \\
\hline \multicolumn{2}{|c|}{ Cement $\left(\mathrm{kg} / \mathrm{m}^{3}\right)$} & 428 & 428 & 428 & 428 & 428 & 428 & 428 & 420 \\
\hline \multirow{2}{*}{$\begin{array}{c}\text { Gravel } \\
\left(\mathrm{kg} / \mathrm{m}^{3}\right)\end{array}$} & $5-9.5 \mathrm{~mm}$ & 885 & 885 & 885 & 885 & 885 & 885 & 885 & \\
\hline & $5-12.7 \mathrm{~mm}$ & & & & & & & & 969 \\
\hline \multicolumn{2}{|c|}{ Sand $\left(\mathrm{kg} / \mathrm{m}^{3}\right)$} & 662 & 662 & 662 & 662 & 662 & 662 & 662 & 684 \\
\hline \multicolumn{2}{|c|}{ Water $\left(\mathrm{kg} / \mathrm{m}^{3}\right)$} & 214 & 214 & 214 & 214 & 214 & 214 & 214 & 210 \\
\hline \multicolumn{2}{|c|}{ Admixture $\left(\mathrm{ml} / \mathrm{m}^{3}\right)$} & 2000 & 2000 & 2000 & 2000 & 2000 & 2000 & 2000 & 1418.5 \\
\hline \multirow{3}{*}{$\begin{array}{c}\text { Fiber } \\
\left(\mathrm{kg} / \mathrm{m}^{3}\right)\end{array}$} & SF & & 40 & 60 & & & & & 40 \\
\hline & PF-A & & & & 5 & & 7 & & \\
\hline & PF-B & & & & & 5 & & 7 & \\
\hline \multicolumn{2}{|c|}{ Notation } & $\mathbf{C C}$ & SF40 & SF60 & PFA5 & PFB5 & PFA7 & PFB7 & SF40_12.7 \\
\hline
\end{tabular}

The type and content of fibers were variables of this study. For that reason, 1 type of steel fiber (SF) and 2 types of macro-synthetic plastic fibers (PF-A and PF-B) were selected. The SF used in M1, M2 and M7 had hooked-ends and was supplied glued in bundles. The PF-A added in mixes M3 and M5 was made of 100\% virgin polypropylene with embossed surface, whereas the PF-B added in mixes M4 and M6 was made of polypropylene/polyethylene. The characteristics of the fibers are presented in detail in Table 2.

Table 2. Characteristics of the fibers

\begin{tabular}{l|c|c|c}
\hline \multicolumn{1}{c|}{ Characteristics } & SF & PF-A & PF-B \\
\hline Length (mm) & 35 & 54 & 51 \\
\hline Diameter (mm) & 0.55 & - & - \\
\hline Aspect ratio (-) & 65 & 70 & 74 \\
\hline Tensile strength (MPa) & 1345 & 585 & $600-650$ \\
\hline Modulus of elasticity (GPa) & 210 & - & 9.5 \\
\hline
\end{tabular}

The properties of fresh concrete were evaluated by performing slump tests, density tests and entrapped air tests according to the standards ASTM C143 [25], ASTM C138 [26] and ASTM C231 [27], respectively. The hardened-state properties of concrete were assessed through compression tests following the standard ASTM C39 [28]. For that, 3 cylinders of $150 \mathrm{~mm}$ x $300 \mathrm{~mm}$ were cast per mix. These specimens were cast in 3 layers; each of them compacted with a vibration table during 25 seconds. After 24 hours, specimens were demoulded and stored in a curing room at $23^{\circ} \mathrm{C}$ and $95 \%$ of relative humidity for 28 days. Table 3 presents the results of the fresh- and hardened-state characterization of the mixes. 
Table 3. Fresh- and hardened-state properties of the mixes

\begin{tabular}{|c|c|c|c|c|c|c|c|c|c|}
\hline \multirow{2}{*}{\multicolumn{2}{|c|}{ Properties }} & \multicolumn{8}{|c|}{ Average values } \\
\hline & & CC & SF40 & SF60 & PF-A5 & PF-B5 & PF-A7 & PF-B7 & SF40_12.7 \\
\hline \multirow{3}{*}{ Fresh-state } & Slump (mm) & 81 & 80 & 77 & 79 & 90 & 80 & 82 & 105 \\
\hline & Density $\left(\mathrm{kg} / \mathrm{m}^{3}\right)$ & 2240 & 2255 & 2247 & 2260 & 2260 & 2250 & 2255 & 2328 \\
\hline & Entrapped air (\%) & 1.7 & 1.5 & 1.8 & 1.6 & 1.3 & 1.7 & 1.7 & 3.5 \\
\hline Hardened-state & $\begin{array}{l}\text { Compressive } \\
\text { strength (MPa) }\end{array}$ & 40 & 40 & 41 & 41 & 40 & 41 & 42 & 42 \\
\hline
\end{tabular}

In general, all mixes present similar results of fresh-state properties. For the FRC compositions, the density decreases and the entrapped air increases as the fiber content increases. Such outcome was expected since the addition of fibers tends to contribute to the occlusion of air in the mix. The slump either remains constant or decreases slightly with the increase of fiber content. The compressive strength is not significantly affected by the inclusion of fiber.

\subsection{Test setup and procedure}

\subsubsection{Luong test}

The Luong test was performed in cylindrical specimens. Before the test, the top and bottom faces of the specimen were notched to achieve the shape depicted in Fig. 1a that should favor a Model II failure. The geometry of the specimen was defined by the height, the diameter, the notch depth and the thickness of the external crown (shortest distance from the notch to the surface of the specimen), as shown in Fig. 1a. In this study, the diameter and the notch depth were equal to $150 \mathrm{~mm}$ and $10 \mathrm{~mm}$, respectively. Other parameters were considered variables.

Metallic rings were placed over the outer perimeter of the notch at the top surface and over the inner part of the notch at the bottom surface. Two sets of rings were manufactured in order to test the specimens with a diameter of notches of $75 \mathrm{~mm}$ and of $100 \mathrm{~mm}$. In the first case, the rings placed at the top and at the bottom surfaces have an external diameter of $97 \mathrm{~mm}$ and $68 \mathrm{~mm}$, respectively. In the second case, the diameters are $123 \mathrm{~mm}$ and 94 $\mathrm{mm}$, respectively. All rings had a width of $10 \mathrm{~mm}$.
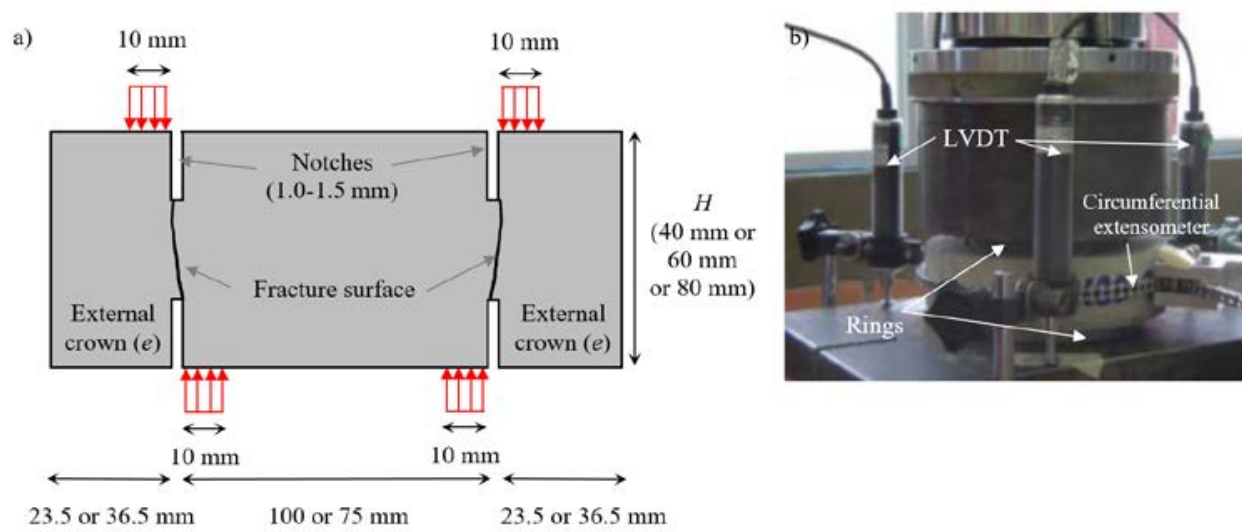

Fig.1 a) Luong test specimen and b) test setup 
During the test, a relative displacement is applied to the opposite surfaces of the rings. This produces a shear loading at the zone between the top and bottom notches and induces the formation of cracks. The test was performed in a MTS servo-hydraulic load frame. The lower piston of the press had an upward displacement rate of $0.1 \mathrm{~mm} / \mathrm{min}$, whereas the top plate located above the specimen was fixed. This procedure was defined in accordance with the results of a previous study by García et al. [29] that characterized the shear behavior of unreinforced sprayed concrete.

The force applied by the press was measured through the test. Likewise, the axial displacement was registered with three LVDT sensors placed vertically around the specimens and separated $120^{\circ}$ from each other (see Fig. 1b). Moreover, the circumferential displacement was measured by means of a circumferential extensometer located at mid-height of the specimen.

\subsubsection{Push-off test}

The push-off test was selected for the comparison with the Luong test. Z-shaped prisms with the dimension indicated in Fig. 2a were used in this study. Using the same MTS servo-hydraulic load frame, a constant upward displacement rate of $0.25 \mathrm{~mm} / \mathrm{min}$ was applied by the lower piston of the press, whereas the plate located above the specimen was fixed. This procedure was defined according to previous experiences in the laboratory, being in line with the work conducted by Lee and Foster [21] (the authors report an initial displacement rate of $0.2 \mathrm{~mm} / \mathrm{min}$ with an increase of $0.1 \mathrm{~mm}$ per minute after cracking). The shear cracks should appear in the vertical region between the notches.

a)

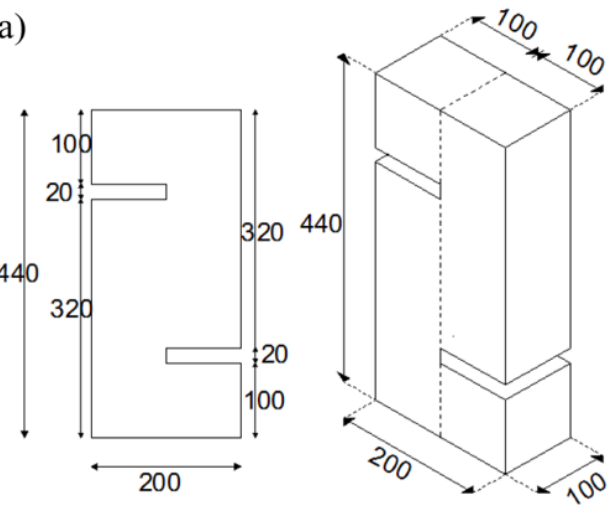

b)

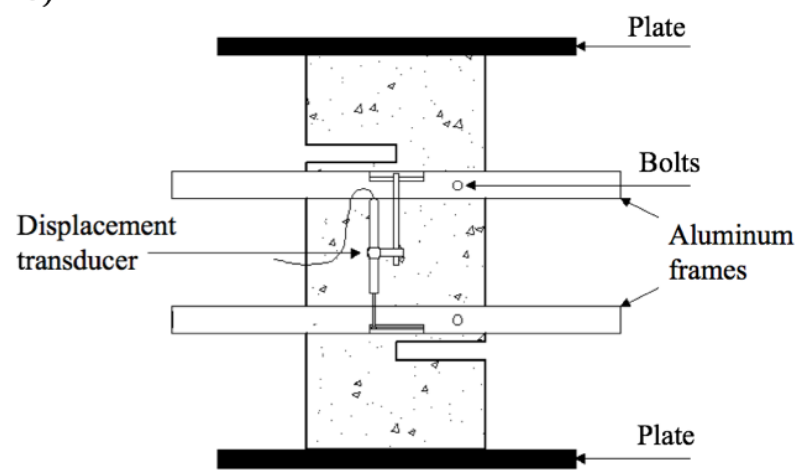

Fig.2 a) Dimensions of the Z-shaped specimen and b) test setup

The force applied, the axial displacement of the piston and the shear displacement at the failure surface were registered during the test. The shear displacement was measured by means of 2 displacement transducers - 1 at each side of the specimen, as shown in Fig. 2b. 


\subsection{Variables of the study}

Fig. 3 summarizes the main variables considered in this study (height $H$, thickness of the external crown $e$, aggregate size, type of fiber and fiber content), as well as the number of samples tested in each case.

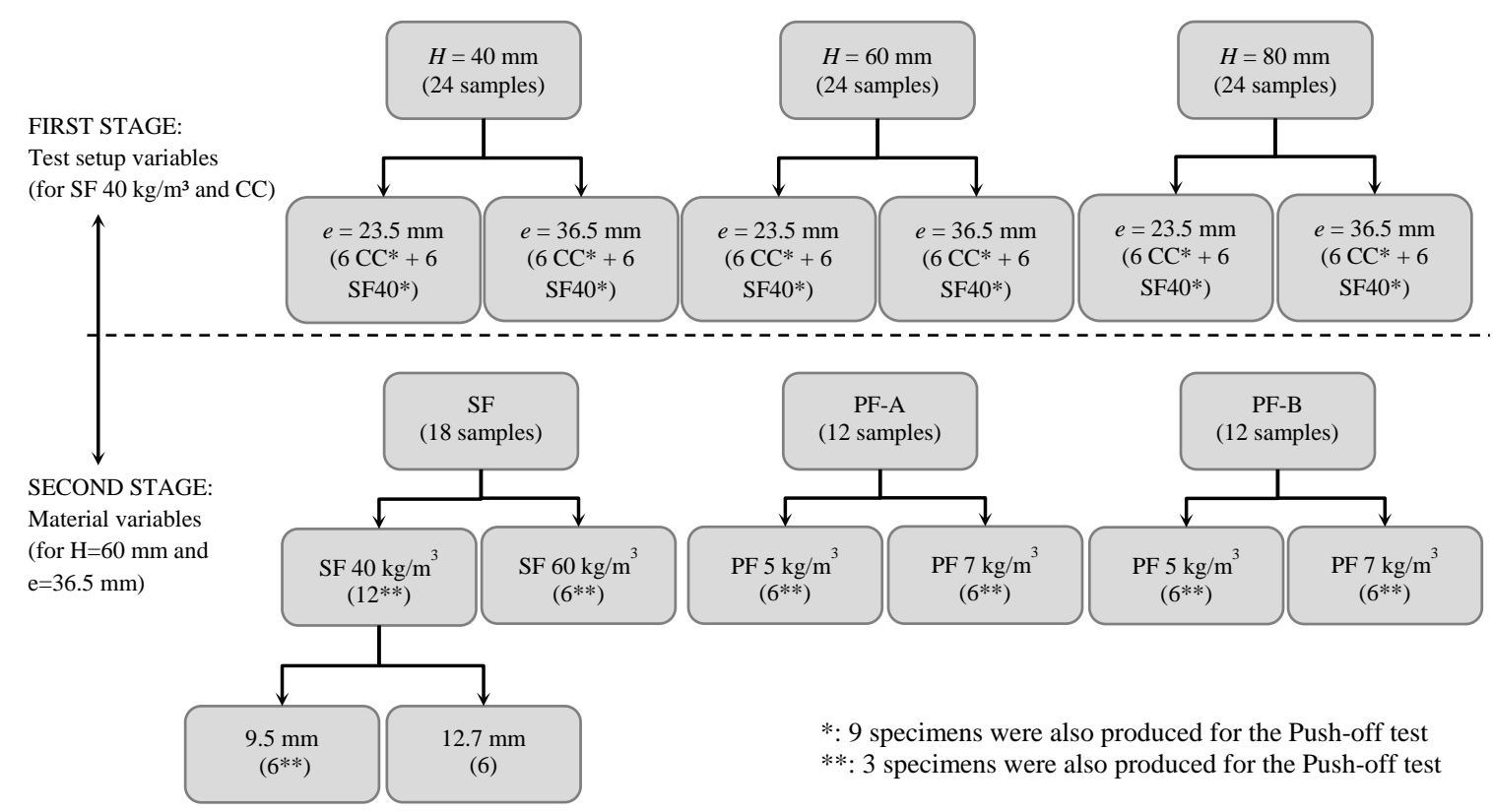

Fig.3 Variables of the study and number of specimens characterized with the Luong test

The first stage of the experimental program focused on the influence of the geometry of the specimen in the results of the Luong test was also assessed. Even though the original height proposed by Luong [7] for the specimen was $40 \mathrm{~mm}$, the heights of $60 \mathrm{~mm}$ and 80 $\mathrm{mm}$ were also considered since the length of the fibers available in the market may be bigger than $40 \mathrm{~mm}$. The dimension of the external crown was determined by the diameter of the drills commercially available, which were $75 \mathrm{~mm}$ and $100 \mathrm{~mm}$. As the external diameter of the cylindrical sample was $150 \mathrm{~mm}$, the thicknesses of the external crown of concrete outside the notch were $36.5 \mathrm{~mm}$ and $23.5 \mathrm{~mm}$, respectively. This variable affects the confinement provided by the external crown and the size of the cracked surface.

For each height evaluated ( $40 \mathrm{~mm}, 60 \mathrm{~mm}$ and $80 \mathrm{~mm}$ ), 12 specimens ( 6 of CC and 6 of SF40) with an external crown of $36.5 \mathrm{~mm}$ were tested. The same also applies to specimens with external crown of $23.5 \mathrm{~mm}$. This makes a total of 72 specimens tested in the first stage.

The second stage of the experimental program focused on evaluating the sensibility of the Luong test to changes in the composition of the FRC. 3 types of fibers (SF, PF-A and PF-B) were considered with 2 contents ( $40 \mathrm{~kg} / \mathrm{m}^{3}$ and $60 \mathrm{~kg} / \mathrm{m}^{3}$ for SF and $5 \mathrm{~kg} / \mathrm{m}^{3}$ and 7 $\mathrm{kg} / \mathrm{m}^{3}$ for PF-A and PF-B). The influence of the aggregate size was evaluated by considering two maximum aggregate sizes: $9.5 \mathrm{~mm}$ (3/8 in) and $12.7 \mathrm{~mm}(1 / 2 \mathrm{in})$. 
To account for these variables, the notation previously described for the fibers and concrete composition will be complemented with the height of the specimen (40, 60 or 80) and the thickness of the external crown (23.5 or 36.5). For example, a specimen reinforced with $40 \mathrm{~kg} / \mathrm{m}^{3}$ of steel fibers, a height of $80 \mathrm{~mm}$ and an external crown of 23.5 mm will be named SF40_80_23.5. Notice that the study of the aggregate size was performed only in specimens with a height of $60 \mathrm{~mm}$, thickness of external crown of 36.5 $\mathrm{mm}$ and a content of $40 \mathrm{~kg} / \mathrm{m}^{3}$ of SF. The notation in this specific case is simplified to SF40_9.5 and SF40_12.7.

Push-off tests were performed with all mixes characterized with the Luong test, except for the one produced with aggregate with maximum size of $12.7 \mathrm{~mm}$ (1/2 in). The nomenclature adopted to refer to the series of the push-off test indicates only the concrete composition.

\subsection{Preparation of the specimens}

In addition to the specimens for the characterization of the compressive strength, 6 cylinders of $150 \mathrm{~mm}$ x $150 \mathrm{~mm}$ and 3 Z-shaped blocks of 100 x 200 x $440 \mathrm{~mm}$ were cast for each series to perform the Luong and the push-off tests, respectively. The unmolding and curing was the same as described previously, expect for the specimens for the Luong test.

These specimens were removed from the curing room at 21 days of age to be cut and notched. First, the cylinders were cut into specimens with the different heights selected (40, 60 and $80 \mathrm{~mm}$ ) using a circular saw-blade. Then, they were notched and placed again in the curing room until the age of testing. The Z-shaped specimens did not require any preparation prior to the push-off tests since the shape was given by the molds used in the casting. The use of these molds may induce a different fiber orientation if compared to specimens cast in regular molds and notched afterwards.

\section{EVALUATION OF THE PUSH-OFF AND LUONG TESTS}

\subsection{Failure mechanism}

In the initial stage of the push-off test, the load applied generates shear stresses between the notches, which are resisted mainly by the cementitious matrix. When the shear strength of the matrix is reached, the main cracks are formed, initiating at the tip of one of the notches and propagating to the tip of the other notch. From this point on, aggregate interlock is responsible for transmitting the shear stresses. In the case of the specimens with fiber, the bridging action of the fibers also contributes to resist the shear stresses in addition to the aggregate interlock.

As further vertical displacement is applied, the crack opening increases because of the dilatancy generated by the aggregates, inducing a horizontal displacement between the two parts of the Z-shaped specimen. Shortly after, the two parts of the Z-shaped specimen with CC are separated due to the limited displacement allowed by the aggregate interlock 
mechanism and the change in the load distribution in the test. In contrast, the test of specimens with fibers continues due to the beneficial contribution of the fibers. The increments of vertical displacement cause additional horizontal displacements that induce bending moments in the cross section. In later stages of the test, these bending moments induce the formation of secondary cracks perpendicular to main cracks formed initially. This failure mechanism is representative of all the samples tested in the experimental program.

Fig. 4a and 4b show the Z-shaped specimens of the series CC and SF60 after the test. In both cases, a vertical crack due to shear is clearly identified connecting the two notches. In the specimens with fibers, secondary cracks also appeared perpendicularly to the main vertical crack (see Fig.4b). The failure mechanism observed in the specimens tested is the same as reported in other studies for plain concrete and FRC [19].
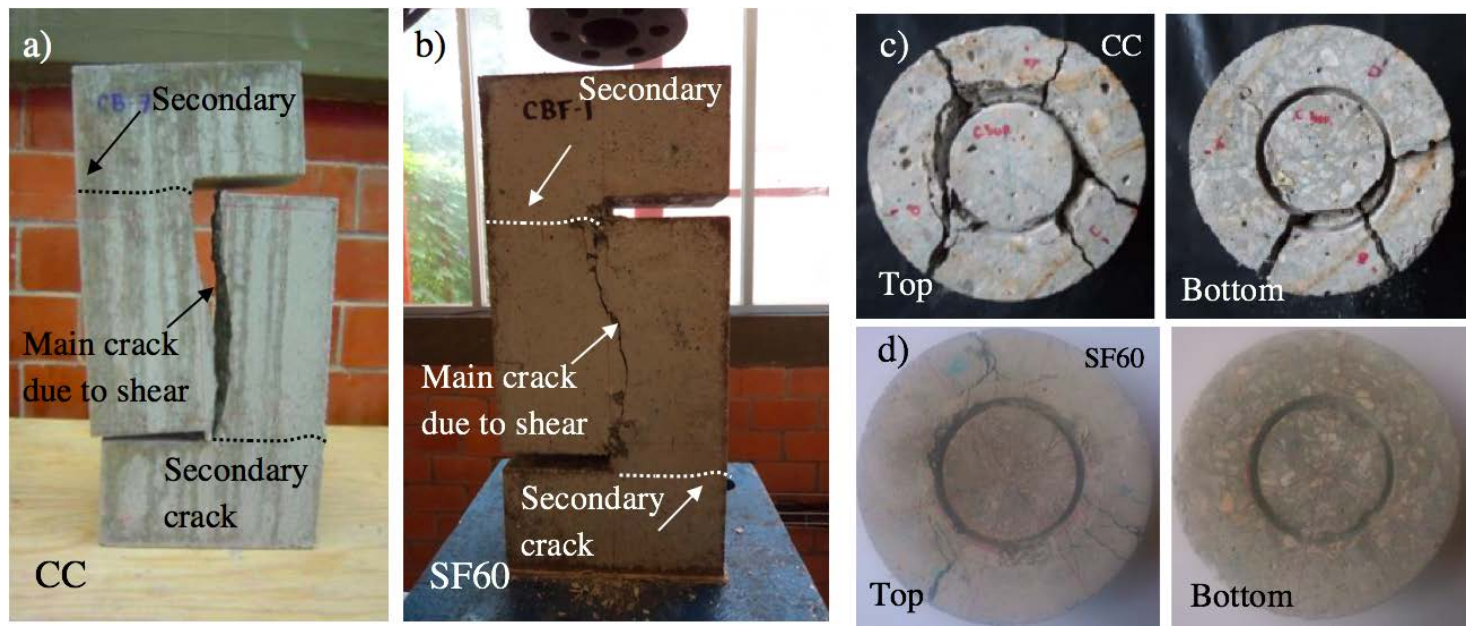

Fig.4 Failure mechanism of the Z-shaped specimens in the push-off tests with a) CC and b) SF40; and of the specimens of the Luong test of c) CC_40_23.5 and of d) SF40_40_23.5

In the Luong test, a vertical cracking surface is also formed between the notches when the shear strength of the matrix is reached. One of the most important aspects to obtain ideal shear failure is the alignment between the shear failure surface and the direction of the displacement applied (see Fig. 4c). In this test, another relevant aspect is the presence of confining stresses generating compressions in the shear failure surface. The compression stresses in the failure surface will affect the shear strength measured during the test but should not affect significantly the evolution of the relative shear displacement. In fact, this confinement contributes to reduce the horizontal opening of the joints and limit the changes in test configuration, favoring the alignment between the shear failure and the direction of displacement applied by the press.

Once the crack appears, the main mechanism governing the shear behavior in CC is the aggregate interlock, whereas the bridging effect of the fibers also contribute in the case of specimens with fiber. As additional displacement is applied, the dilatancy generate by the aggregates cause tensile stresses in the external crown. At later stages of the test, these tensile forces increase and generate radial cracks in the external crown (see Fig. 4d). The 
formation of these cracks reduces the confinement of the region surrounding the shear crack and, as a result, the shear capacity in the interface also decreases. However, the main bearing mechanism is still shear.

Fig. 4c and 4d show specimens with CC and SF_60 after the Luong Test. All of them present a main crack that follow the notch and secondary cracks that run along the thickness of the external crown. The secondary cracks are clearly visible in the specimen with CC, being several times smaller in the case of the specimens with FRC. Even though the response obtained in the Luong test should not be generalized to the expected in a real-scale element, a parallel can be drawn. In both of them, boundary conditions or the concrete around the cracked surface tend to introduce a certain confinement that diminishes as the damage evolves. This reduction of confinement will be more evident in CC than in FRC, as observed by the crack pattern of the specimen after the Luong test.

\subsection{Load-displacement curves}

Fig. $5 \mathrm{a}$ and $5 \mathrm{~b}$ show the load-displacement curves obtained in the push-off test for CC and SF60 specimens, respectively. Curves of individual tests are represented in grey scale, while the average curve of each series is depicted in full dark color. The push-off test show an increase of the load accompanied by a consequent increase in the displacement measured. Once a maximum load is reached, the shear crack develops. At this moment, a slight relative movement occurs between the two parts of the Z-shaped specimens, changing the load configuration of the original setup.
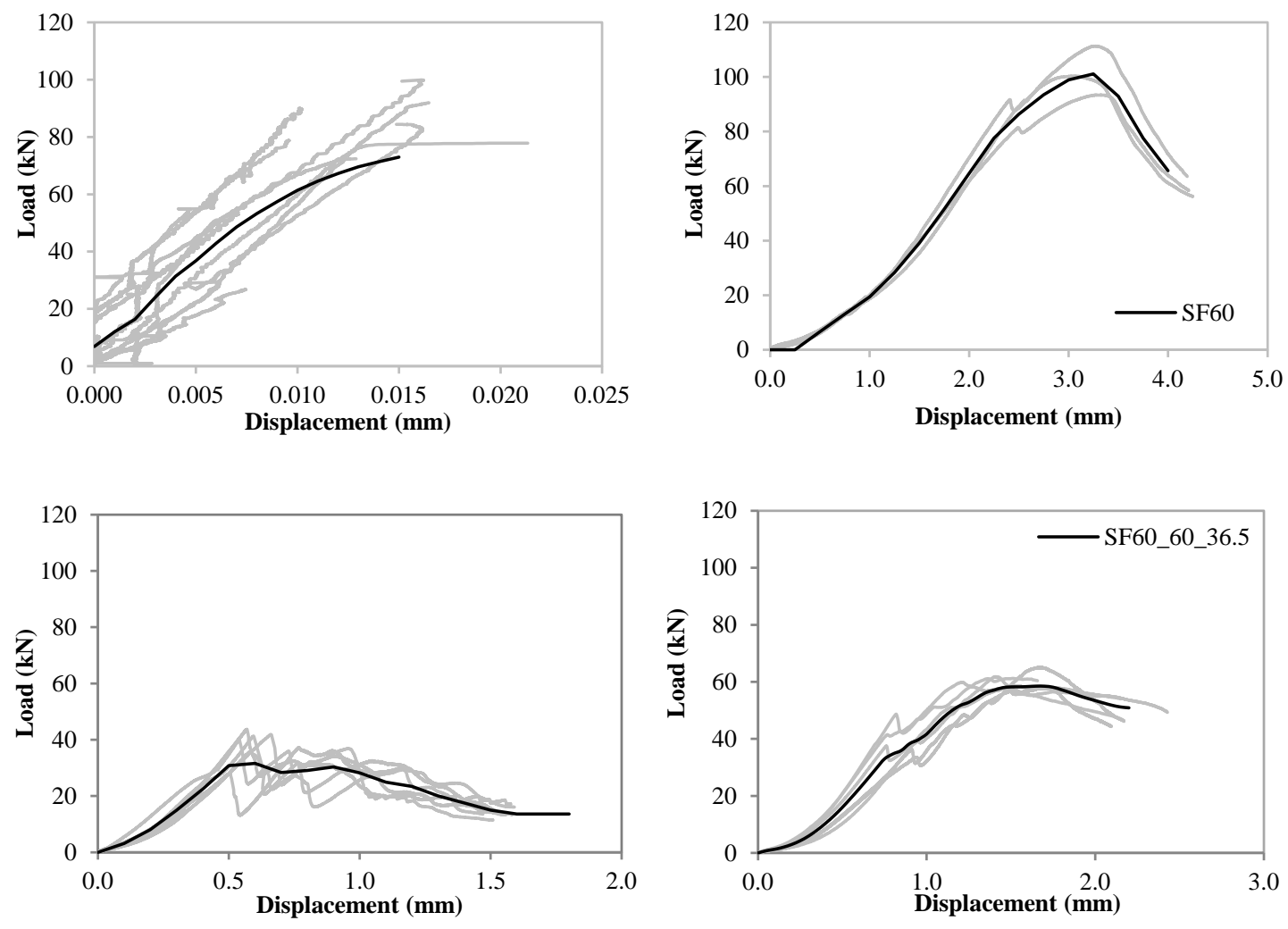

Fig.5 Load-displacement curves of the push-off test and Luong test 
In the case of the specimen with CC, the test is interrupted at a displacement smaller than $0.25 \mathrm{~mm}$ since the dilatancy experienced by the aggregates produce the complete separation of the two parts of the Z-shaped specimen. In the case of specimens with FRC, a loss of stiffness is observed until a displacement that mobilizes the contribution of the fiber is reached. After that, higher loads are reached.

Fig. 5c and 5d show the load-displacement curves obtained in the Luong test for equivalent specimens with CC and SF60. In both cases, specimens with a height of 60 $\mathrm{mm}$ and an external crown of $32.5 \mathrm{~mm}$ are considered. A settlement is observed at the beginning of the curve given that the contact between the metallic rings where the load is applied and the FRC disk is not perfect. Once the irregularities are reduced and the full contact is established, an approximately linear-elastic behavior is observed until the shear strength of the matrix is reached. In subsequent analyses, the data obtained from the test is treated to remove the settlement and the results will be presented in terms of shear stress.

The load increases until the crack is formed, producing a slight loss of stiffness characterized by the reduction of the load. After this point, CC specimens show a decrease in the load, whereas the SF60 specimens show an increase in the load bearing capacity, whereas due to the action of the fibers.

The Luong test reach displacements close to $1.5 \mathrm{~mm}$ for the specimen with CC. This value is several times bigger than the maximum reached in the push-off test for the same concrete composition, thus confirming the higher stability of the former. As mentioned in previous section, the confinement introduced by the external crown contributes to maintain the load configuration despite the dilatancy forces, allowing the measurement of the response to proceed after the crack is formed.

\subsection{Shear strength}

Table 4 presents the maximum shear strength and the coefficient of variation $(C V)$ for the push-off and the Luong tests. The shear strength was estimated for each specimen by dividing the maximum load registered during the test by the ideal shear failure surface assumed as the minimum area between notches. 


\begin{tabular}{|c|c|c|c|c|}
\hline Concrete & Test & Type of specimens & Shear strength (MPa) & $C V(\%)$ \\
\hline \multirow{7}{*}{$\mathrm{CC}$} & \multirow{6}{*}{ Luong test } & CC_40_23.5 & 3.0 & 15.2 \\
\hline & & CC_40_36.5 & 3.6 & 18.0 \\
\hline & & CC_60_23.5 & 3.1 & 7.2 \\
\hline & & CC_60_36.5 & 4.3 & 6.7 \\
\hline & & CC_80_23.5 & 3.6 & 20.5 \\
\hline & & CC_80_36.5 & 3.8 & 11.7 \\
\hline & Push-off test & $\mathrm{CC}$ & 3.9 & 4.6 \\
\hline \multirow{8}{*}{ SF40 } & \multirow{7}{*}{ Luong test } & SF40_40_23.5 & 4.7 & 7.1 \\
\hline & & SF40_40_36.5 & 5.8 & 14.7 \\
\hline & & SF40_60_23.5 & 5.2 & 11.1 \\
\hline & & SF40_60_36.5 & 5.9 & 7.0 \\
\hline & & SF40_60_36.5_12.7 & 7.2 & 13.4 \\
\hline & & SF40_80_23.5 & 5.0 & 7.3 \\
\hline & & SF40_80_36.5 & 5.4 & 10.8 \\
\hline & Push-off test & SF40 & 4.6 & 6.2 \\
\hline \multirow{2}{*}{ SF60 } & Luong test & SF60_60_36.5 & 6.4 & 4.2 \\
\hline & Push-off test & SF60 & 4.9 & 8.5 \\
\hline \multirow{2}{*}{ PF-A5 } & Luong test & PF-A5_60_36.5 & 4.6 & 16.5 \\
\hline & Push-off test & PF-A5 & 4.9 & 5.3 \\
\hline \multirow{2}{*}{ PF-A7 } & Luong test & PF-A7_60_36.5 & 4.8 & 8.4 \\
\hline & Push-off test & PF-A7 & 4.8 & 2.9 \\
\hline \multirow{2}{*}{ PF-B5 } & Luong test & PF-B5_60_36.5 & 4.4 & 12.4 \\
\hline & Push-off test & PF-B5 & 4.7 & 10.6 \\
\hline \multirow{2}{*}{ PF-B7 } & Luong test & PF-B7_60_36.5 & 4.7 & 9.4 \\
\hline & Push-off test & PF-B7 & 4.4 & 8.3 \\
\hline
\end{tabular}

Table 4 reveals that both tests yield values of maximum shear stress that are in the same order of magnitude for the specimens with and without fibers. A Mann-Whitney U test was performed to evaluate the statistical significance of the differences. This is a nonparametric test for the comparison of two samples that may not follow a normal distribution or with small number of elements per sample. A significant level ( $\alpha$ ) of 0.050 was taken as a reference for all comparisons. If the p-value obtained with the MannWhitney $\mathrm{U}$ test is smaller than $\alpha$, the null hypothesis is rejected and the average of the samples are considered different from each other.

No statistically significant difference is found between the shear strength measured with the Luong test for CC specimens with external crown of $36.5 \mathrm{~mm}$ of any height and the push-off test with $\mathrm{CC}$ specimens (p-values $\geq 0.175$ ). On the contrary, significant differences are observed for all heights in the case of the Luong using CC specimens with external crown of $23.5 \mathrm{~mm}$ with heights of $40 \mathrm{~mm}$ and $60 \mathrm{~mm}$, which give average shear force $21.8 \%$ smaller than in the push off test (p-values $\leq 0.016$ ).

For samples with fibers, no significant difference was found between both tests, regardless of the thickness of the external crown (p-values $\geq 0.052$ ). The only exception was observed for the specimens SF60 (p-value $=0.024$ ) due to the anomalous shear strength obtained in the push-off test that were even smaller than the obtained for SF40 with the same test. 
The table reveals that the increase of fiber content leads to a consequent increase of the shear strength evaluated with the Luong test of $8.5 \%, 4.3 \%$ and $6.8 \%$ for series SF, PF-A and PF-B, respectively. Such percentages are smaller in the case of the push-off test (6.5\%, $4.3 \%$ and $-9.3 \%$, respectively). These results suggest that the Luong test is more sensitive to the increase of the content of fiber than the push-off test. This outcome may be justified by the contribution of the fibers to the confinement, which is only taken into account in the Luong test.

The variability of the results of the Luong test is consistently higher than that measured with the push-off test ( $\mathrm{p}$-value $=0.026$ ). This may be attributed to the size of the failure surface characterized in each test. A theoretical failure area ranging from $48.4 \mathrm{~cm}^{2}$ to $194.2 \mathrm{~cm}^{2}$ of the Luong test, which is smaller than theoretical failure area of $200 \mathrm{~cm}^{2}$ of push-off test. As described by Cavalaro [30], a reduction of the intrinsic scatter related with the variability in the fibers contributing to bridge the crack should be expected as the failure surface increases. Consequently, the smaller failure area of the Luong test should induce higher scatter than the expected in the push-off test.

\section{SENSITIVITY ANALYSIS OF THE LUONG TEST}

\subsection{Influence to the height of the specimen}

Fig. 6a presents the shear stress-displacement curves for SF40 specimens with external crown of $23.5 \mathrm{~mm}$ and with three different heights (40 mm, $60 \mathrm{~mm}$ and $80 \mathrm{~mm}$ ). Again, the curve of each specimen is presented in a gray scale and the average of the series is depicted in full dark color. The post-cracking response is analyzed in terms of specific absorbed energy, estimated as the average area below the shear stress-displacement curve (see average values for all samples in table from Fig.6a).
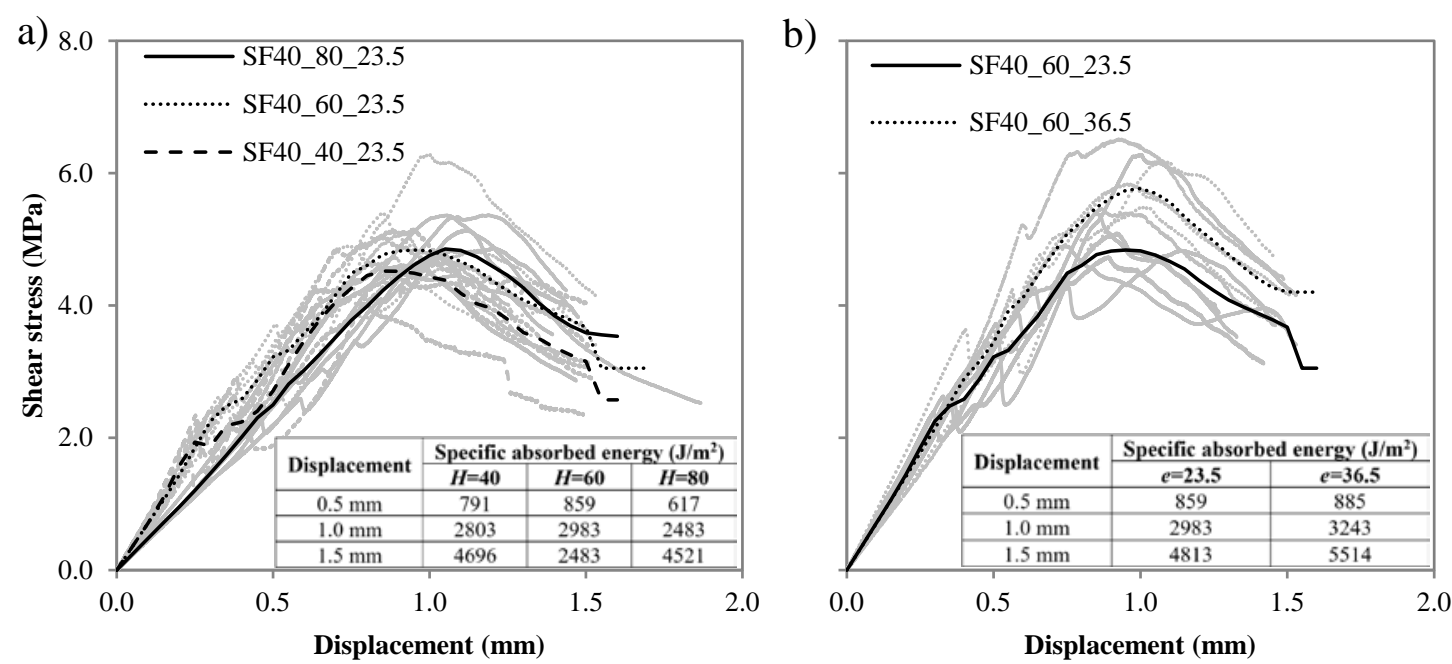

Fig.6 Shear stress-displacements curves to evaluate a) influence of the height of the specimen and b) influence of diameter of the notch 
The stiffness of the initial part of the curves of specimens with $40 \mathrm{~mm}$ and $60 \mathrm{~mm}$ of height are higher than the observed for the specimens with $80 \mathrm{~mm}$ of height. Moreover, the displacement for which the maximum shear stress is observed reduces as the height of the specimen decreases. Both observations suggest a more fragile behavior of the specimens with $40 \mathrm{~mm}$ and $60 \mathrm{~mm}$ in comparison with the observed in the specimens with $80 \mathrm{~mm}$.

The specific absorbed energy also reveals differences in the response measured during the test depending on the height of the specimen. For displacements of $0.5 \mathrm{~mm}, 1.0 \mathrm{~mm}$ and $1.5 \mathrm{~mm}$ no statistical difference exists between the results for specimens with height of $40 \mathrm{~mm}$ and $60 \mathrm{~mm}$ ( $\mathrm{p}$-value $\geq 0.230$ ). On the contrary, smaller values are found between these specimens and the specimens with $80 \mathrm{~mm}$ of height for displacements of $0.5 \mathrm{~mm}$ and $1.0 \mathrm{~mm}$.

The differences in behavior highlighted in previous paragraphs may be related to the proportion of the height of the specimen that is notched to favor the mode II failure. Since the depth of the notch is maintained in all cases $(10 \mathrm{~mm}$ at the top face and $10 \mathrm{~mm}$ at the bottom face), a reduction of $50 \%$ and $33 \%$ of the total height is produced in specimens with $40 \mathrm{~mm}$ and $60 \mathrm{~mm}$, respectively. In contrast, a reduction of $25 \%$ is induced in the specimen with $80 \mathrm{~mm}$. The smaller reduction found in specimens with $80 \mathrm{~mm}$ increases the likelihood of developing alternative failure planes that deviates from the ideal failure expected in shear, leading to a different behavior.

The loads applied to the specimen by steel ring could also induce a change in the cracking surface. This load produces a complex stress state in the region close to the notch and in contact with the steel ring. In this context, the higher load levels reached in the specimen with $80 \mathrm{~mm}$ of height could favor a deviation of the main crack formed during the test.

Fig. 7 shows an example of the deviation of the cracking plane experienced by several specimens with height of $80 \mathrm{~mm}$. Notice that due to the depth of the notch and the influence of the metallic rings, circumferential cracks appear outside the ideal plane of failure (see crack in the top surface). To mitigate this undesired behavior, the depth of the notch of specimens with $80 \mathrm{~mm}$ of height should be increased to favor a failure closer to purer shear.
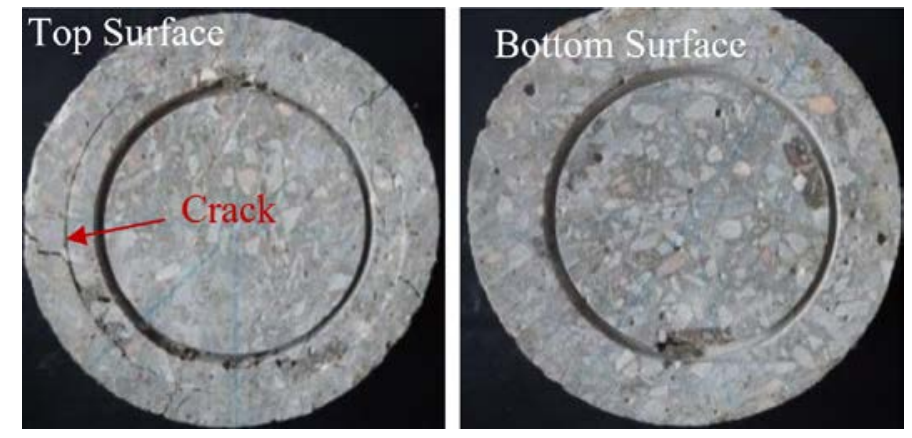

Fig.7 Cracking of a specimen with height of $80 \mathrm{~mm}$ suggesting the deviation of the main crack 


\subsection{Influence of the thickness of the external crown}

Fig.6b presents the shear stress-displacement curves of all specimen of the series SF40_60 with external crown of 23.5 mm (SF40_60_23.5) and with external crown of $36.5 \mathrm{~mm}$ (SF40_60_36.5). The average curve of each series is also presented in the same figure. The comparison of both series reveal that the average shear strength for the series with thickness of external crown of $36.5 \mathrm{~mm}$ is $14.0 \%$ higher than that of series with thickness of external crown of 23.5 (p-value $=0.045$ ).

In terms of specific absorbed energy for $0.5 \mathrm{~mm}, 1.0 \mathrm{~mm}$ and $1.5 \mathrm{~mm}$, series with 36.5 mm show values $3.0 \%, 12.0 \%$ and $17.8 \%$ bigger than the ones obtained for equivalent specimens with $23.5 \mathrm{~mm}$ (see table in Fig. 6b). The differences observed for the displacement of $0.5 \mathrm{~mm}$ are not statistically significant (p-value $=0.411$ ). Such outcome is reasonable since the first crack (characterized by a drop in the shear stress) occurs for a displacement close to $0.5 \mathrm{~mm}$. Therefore, the energy measured up to this point is mainly the result of the nearly elastic branch, being scarcely affected by the fiber contribution and the confinement provided by the external crown.

On the other hand, differences observed for displacements of $1.0 \mathrm{~mm}$ and $1.5 \mathrm{~mm}$ are statistically significant ( $\mathrm{p}$-value $\leq 0.036$ ). In both cases, the shear cracks are fully developed so that the confinement provided by the external crown is activated. Consequently, higher specific absorbed energy and shear strength should be reached for the specimens with bigger external crown, which generates bigger confinement.

Another factor that could also contribute to this result is the influence of the molds used to cast the specimens in the fiber orientation. As highlighted in several studies, fibers tend to align parallel to the formwork as their position approach the surface of the mold, in a phenomenon called wall-effect. As the thickness of the external crown reduces, the shear failure plane should get closer to the molded surface. In this scenario, a bigger proportion of fibers will tend to aligned parallel to the mold and to the shear failure plane. Consequently, less fibers would cross the failure plane and contribute to the shear response in the case of thickness of external crown of $23.5 \mathrm{~mm}$ in comparison with that found in the case of an external crown of $35.6 \mathrm{~mm}$. This may justify the bigger shear strength and specific absorbed energy consistently measured in the latter. Notice that same trends described in this section were observed for almost all series, regardless of the height of the specimen and the material used (CC and FRC).

\subsection{Influence of the aggregate size}

The influence of the aggregate size on the shear response of FRC is evaluated through the shear-stress displacement curves in Fig. 8. The curves reveal that the increase of the aggregate size from $9.5 \mathrm{~mm}$ to $12.7 \mathrm{~mm}$ leads to a consequent increase of $22.0 \%$ in the average shear strength ( $p$-value $=0.020$ ). This is consistent with other studies from the literature [31,32] that conclude that an increase of the aggregate size causes a consequent increase in the shear resistant capacity due to the higher interlocking effect generated. 


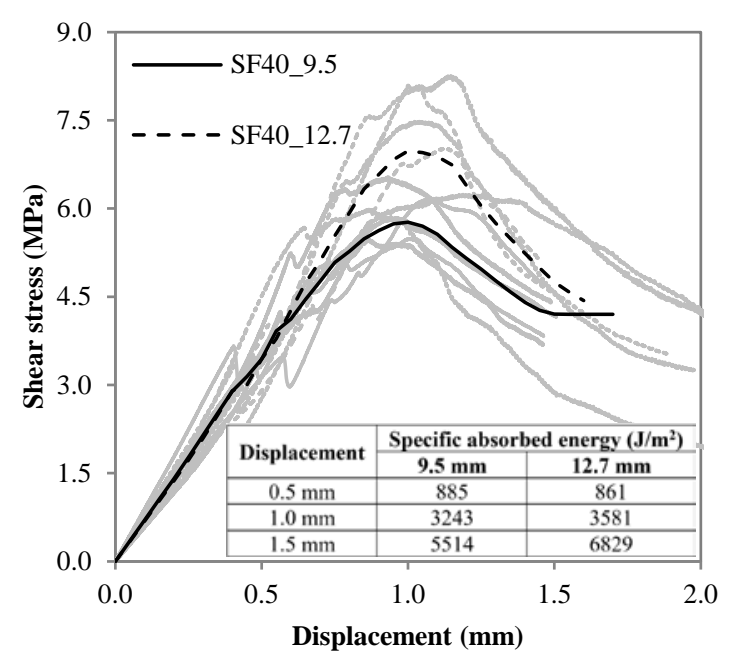

Fig.8 Shear stress-displacements curves to evaluate the influence of the maximum aggregate size

Nevertheless, the influence of the maximum size of the aggregate in the specific absorbed energy are only clearly perceived for high displacements. For the displacements of 0.5 $\mathrm{mm}$ and $1.0 \mathrm{~mm}$, even though higher values are reached in the case with bigger maximum size aggregate, differences are not statistically significant (p-value $\geq 0.411$ ). Conversely, for the displacement of $1.5 \mathrm{~mm}$, the specific absorbed energy is 20.5 higher in the composition with maximum size aggregate of $12.7 \mathrm{~mm}$ in comparison with the composition with maximum size aggregate of $9.5 \mathrm{~mm}$ (p-value $=0.022$ ). This is outcome is reasonable since the influence of the aggregate interlock should occur once the shear cracks are generated and a certain relative displacement takes place.

\subsection{Influence of type and content of fiber}

The influence of the type of fiber is analyzed through the shear stress-displacement curves in Fig. 9a for the mixes SF60, PF-A7 and PF-B7. Hereinafter the height of the specimens is $60 \mathrm{~mm}$ and the thickness of the external crown is $36.5 \mathrm{~mm}$.

The curves in Fig. 9a reveal that, once the main shear cracks are formed, mixes with the higher content of polymeric fiber (PF-A7 and PF-B7) show a more pronounced reduction of the shear stress in comparison with the mix with the higher content of steel fiber (SF60). This may be attributed to the lower elastic modulus of polymeric fiber, which require bigger displacement in order to start bridging the crack. After this first drop, as fibers become active, the stress resisted increases. Again, this increase is considerably bigger for mixes with steel fiber due to their higher bridging capacity in comparison with plastic fibers. This is in line with findings of other authors [33,34].

The shear strength of SF60 is respectively 33.3\% and 37.8\% bigger than those of PF-A7 and PF-B7 (p-value $\leq 0.020$ ). Differences in terms of the specific absorbed energy are statistically significant for displacements of $1.5 \mathrm{~mm}$ (p-value $\leq 0.002$ ). For this displacement, the specific absorbed energy of SF60 is $32.0 \%$ and $26.7 \%$ bigger than the estimated for PF-A7 and PF-B7. Even though generally higher values are observed for 
the composition with steel fiber, differences were not statistically significant for smaller displacements due to the limited contribution of the fibers in the initial stages of the test. Despite that, the Luong test was sensitive to the differences between metallic and plastic fibers.

The comparison between PF-A7 and PF-B7 does not show any statistically significant difference in terms of the shear strength or the specific absorbed energy ( $p \geq 0.289$ ). Apparently, the variation in the characteristics of the plastic fibers were not enough to induce differences in the results of the Luong test.
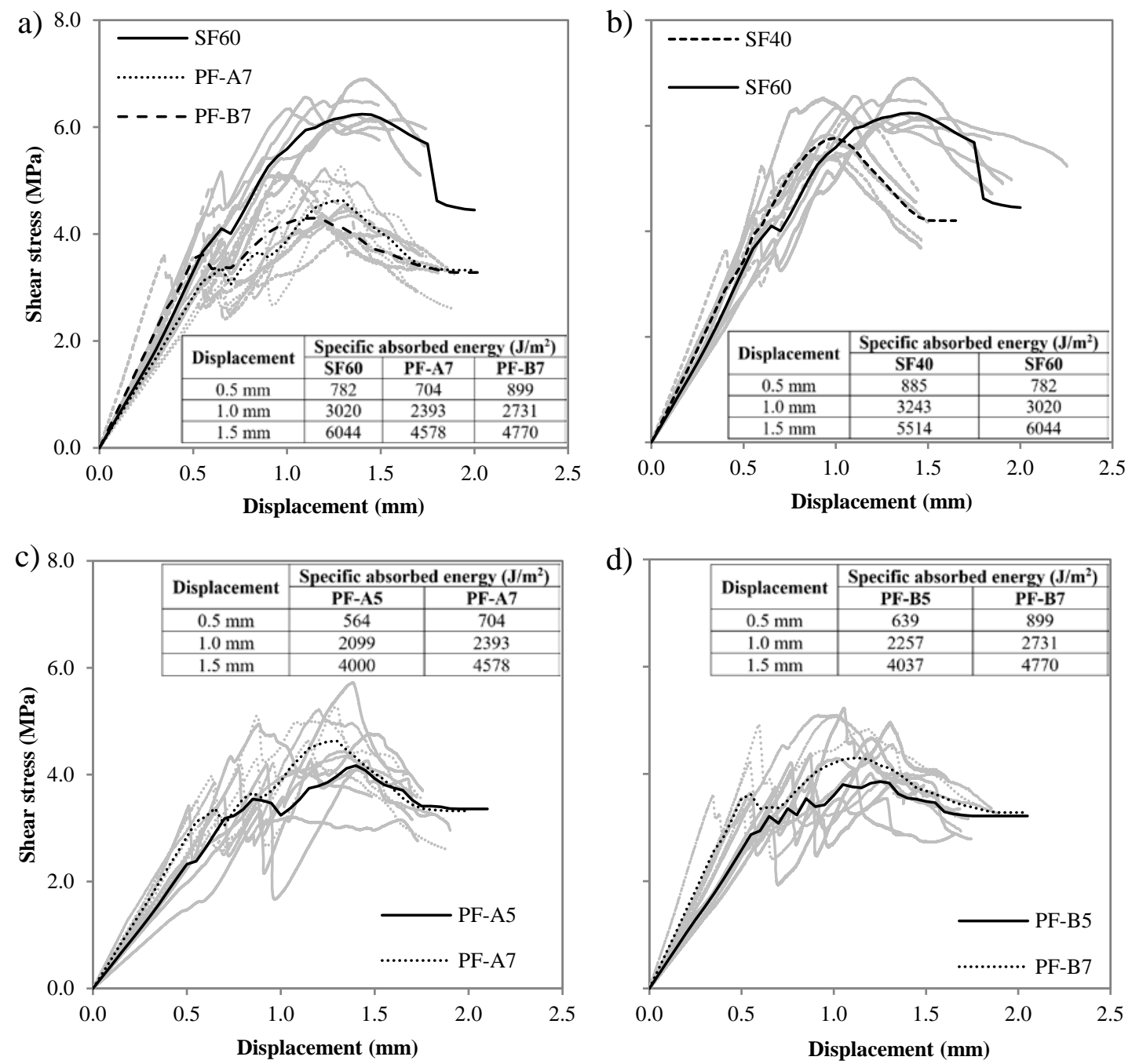

Fig.9 Shear stress-displacements curves to evaluate: a) influence of type of fiber; influence of fiber content: b) SF, c) PF-A and d) PF-B

Fig. 9b, 9c and 9d show the influence of fiber content through the load-displacement curves for the FRC compositions. According to the results in Fig. 9b, the increase in the content of steel fiber leads to a consequent increase of $9.5 \%$ in the shear strength, which is statistically significant ( $\mathrm{p}$-value $=0.045$ ). The same is also observed in terms of the specific absorbed energy for a displacement of $1.5 \mathrm{~mm}$ that was increased by $9.6 \%$ due to the increment of the fiber content $(\mathrm{p}$-value $=0.036)$. 
The increment in the content of both types of plastic fibers lead to a consequent increase of the shear strength of $6.0 \%$ for PFA and of $5.8 \%$ for PFB, although they are not statistically significant due to the variability of the results $(p \geq 0.3 .78$ ). In contrast, statistically significant differences were observed for the specific absorbed energy for the displacement of $1.5 \mathrm{~mm}$ ( $\mathrm{p} \leq 0.045)$. This parameter was increased by $14.4 \%$ for PFA and by $18.1 \%$ for PFB as the fiber content increases. All results confirm that the Luong test is sensitive to variations in the content of metallic and plastic fibers.

\section{RELIABILITY OF THE LUONG TEST}

The reliability of the test is evaluated through the coefficient of variation of the shear strength and of the specific absorbed energy for a displacement of $1.0 \mathrm{~mm}$ and $1.5 \mathrm{~mm}$, as shown in Fig. 10. Only specimens with maximum aggregate size of $9.5 \mathrm{~mm}$, height of $60 \mathrm{~mm}$ and thickness of external crown of $36.5 \mathrm{~mm}$ were included in this analysis.

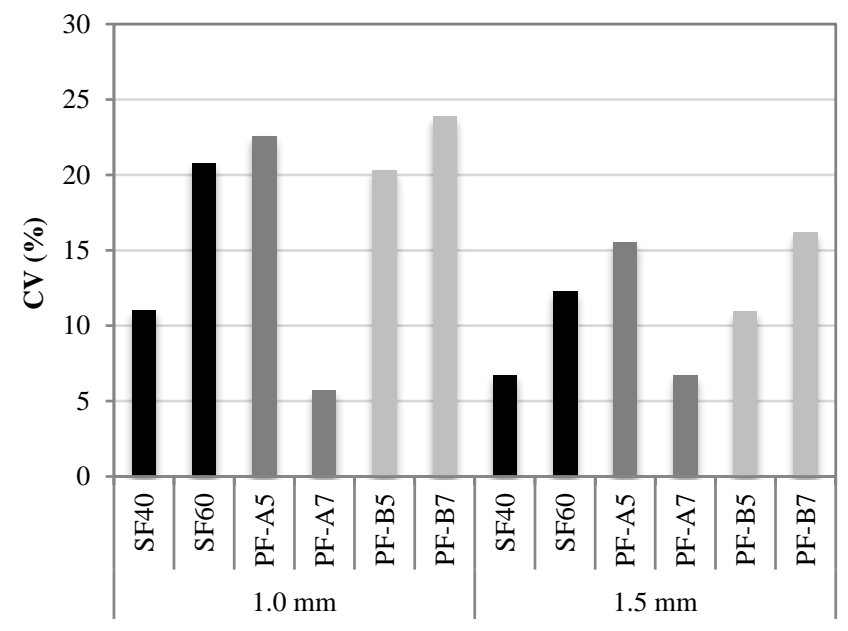

Fig.10 Coefficient of variation (CV) of shear strength and absorbed energy

No clear relation between content or type of fiber and the scatter is found in the results. This outcome differs from those described in other studies from the literature that report a reduced scatter in the tensile response with macro-synthetic fibers and with higher contents due to the larger number of fibers in the concrete matrix [35-38].

The CV of the specific absorbed energy reduces as the displacement increases, which may also be observed tests of the residual response of FRC. This may be explained by the higher variability experienced during the crack formation process and the change in the resistant mechanism when the stresses are transmitted from the matrix to the fibers. The consideration of smaller displacements makes the results more influenced by such variability. As the displacement increases, a higher stability in the response is reached and the effect of the variability is diluted, thus leading to lower scatter. This is especially evident in the case of the Luong test since several drops in the shear stress-displacement curve occur shortly after cracking. 
The average CV of the shear strength (9.5\%) tends to be smaller than the CV of the specific absorbed energy (17.4\% for displacement of $1.0 \mathrm{~mm}$ and $11.4 \%$ for displacement of $1.5 \mathrm{~mm}$ ). All values are small considering the high coefficients of variation reported in the literature for typical tests of the residual tensile response of FRC [39-41].

\section{CONCLUSIONS}

The study proposes the use of the Luong test for the simplified assessment of the direct shear response of FRC. The following conclusions may be derived based on the analyses conducted here.

- The shear strength measured with the Luong test is similar to the obtained with the push-off test for the same concrete. Even though no noticeable differences in terms of stability was observed for mixes with fibers, the test performed with conventional concrete suggest that the Luong test tends to be more stable than the push-off test. This difference in stability in favor of the Luong test could also appear in case of the characterization of concrete reinforced with small fiber contents. Additional studies should be performed to confirm such conjecture.

- The thickness of the external crown determines the confinement provided by the specimen to the failure surface during the test. Based on the results obtained, a height of $60 \mathrm{~mm}$ and the external crown of $36.5 \mathrm{~mm}$ are recommended for future applications of the Luong test with specimens of $150 \mathrm{~mm}$ of diameter, notched to a depth of $10 \mathrm{~mm}$.

- The study about the influence of two aggregate sizes on the shear response of FRC indicates that an increment of the stress-bearing capacity is detected when the maximum size increases. This outcome was already observed by other authors as a consequence of the higher interlocking provided by bigger aggregates.

- The Luong test is sensitive to the type and content of fiber. Mixes with steel fibers exhibited a better performance than mixes with plastic fibers. Likewise, the increase of the fiber content led to an enhanced shear performance. In order to detect the influence of the content of fiber in the post-cracking stage, displacements larger than $1.0 \mathrm{~mm}$ should be reached during the test.

- The scatter of the test is smaller than the typically associated with the measurement of other post-cracking properties of FRC. As a reference value, a coefficient of variation of approximately $15 \%$ may be expected in the Luong test for both the absorbed energy and the shear strength.

- Shear strength and the absorbed energy are the parameters measured in the Luong test that provided the clearest assessment of the influence of the fiber type and content. If possible, evaluations in terms of stresses resisted for specific crack displacements should be avoided since they are prone to local variations during shear failure, yielding higher scatter and not so clear comparisons. 


\section{ACKNOWLEDGEMENTS}

The experimental program was conducted in the Laboratory of Structures and Materials of the Institute of Engineering of the UNAM in Mexico. The authors acknowledge the Institute of Engineering of the UNAM and the International Partnership Fund of the Institute of Engineering of the UNAM for the support in the Partnership Projects of 2014. Likewise, the authors would like to thank the companies Euclid (in particular to Alma Reyes and Víctor Sánchez), BASF (Jorge Esqueda) and Bekaert (Carlos Frutos) for their support in the performance of the experimental program. The authors also acknowledge the collaboration of the postgraduate students Gabriela Zárate and Carlos Ruelas. Finally, the third author acknowledges the support of the scholarship PDJ granted by Departament d'Universitats, Recerca i Societat de la Informació de la Generalitat de Catalunya.

\section{REFERENCES}

1. Balázs GL (2010) A historical review of shear. In: fib Bulletin 57 Shear and punching shear in RC and FRC elements, International Federation for Structural Concrete, Lausanne, pp:1-13.

2. di Prisco M, Plizzari G and Vandewalle L (2010) MC2010: overview on the shear provisions for FRC. In: fib Bulletin 57 Shear and punching shear in RC and FRC elements, International Federation for Structural Concrete, Lausanne, pp: 61-75.

3. RILEM TC162-TDF (2003) Test and design methods for steel fibre reinforced concrete - $\sigma-\mathrm{e}$ design method-final recommendation, Mater Struct, 36(8):560-567. doi: 10.1007/BF02480834.

4. CNR. CNR-DT 204/2006 (2006) Guide for the design and construction of fiber-reinforced concrete structures. Italian National Research Council, Rome.

5. CPH (2008) Instrucción del Hormigón Estructural EHE-08, Comisión Permanente del Hormigón, Ministerio de Fomento, Madrid.

6. fib (2010) Model Code for Concrete Structures 2010, International Federation for Structural Concrete, Lausanne.

7. Luong MP (1990) Tensile and shear strengths of concrete and rock, Eng Fract Mech, 35(1-3):127135.

8. Imam M, Vandewalle L, Mortelmans F and Van Gemert D (1997) Shear Domain of FibreReinforced High-Strength Concrete Beams, Eng Struct, 19(9):738-747. doi:10.1016/S01410296(96)00150-2.

9. Khuntia M, Stojadinovic B and Goel S (1999) Shear Strength of Normal and High-Strength Fibre Reinforced Concrete Beams without Stirrups, ACI Struct J, 96(2):282-289.

10. Kwak YK, Eberhard MO, Kim WS and Kim J (2002) Shear strength of Steel Fiber-Reinforced Concrete Beams without Stirrups, ACI Struct J, 99(4):530-538.

11. Meda A, Minelli F, Plizzari GA and Riva P (2005) Shear behaviour of steel fibre reinforced concrete beams, Mater Struct, 38:343-351. doi: 10.1007/BF02479300.

12. Turmo J, Banthia N, Gettu R and Barragán B (2008) Study of the shear behavior of fibre reinforced concrete beams, Mater Construcc, 58(292):5-13. doi: 10.3989/mc.2008.40507

13. Dinh HH, Parra-Montesinos GJ and Wight J (2010) Shear Behavior of Steel Fiber-Reinforced Concrete Beams without Stirrup Reinforcement, ACI Struct J, 107(5):597-606.

14. Minelli F and Plizzari GA (2013) On the Effectiveness of Steel Fibers as Shear Reinforcement, ACI Struct J, 110(3):379-389.

15. Cuenca E, Echegaray-Oviedo J, Serna P (2015) Influence of concrete matrix and type of fiber on the shear behavior of self-compacting fiber reinforced concrete beams, Compos Part B-Eng, 75:135-147. doi: 10.1016/j.compositesb.2015.01.037

16. Barr B (1987) Fracture Characteristics of FRC Materials in Shear, Fiber Reinforced Concrete Properties and Applications, SP-105, American Concrete Institute, Detroit, pp. 27-53.

17. Balaguru P and Dipsia MG (1993) Properties of fiber reinforced high-strength semi-lightweight concrete, ACI Mater J, 90(5), 399-405.

18. Valle M and Büyüköztürk O (1993) Behaviour of fiber reinforced high-strength concrete under direct shear, ACI Mater J, 90(2), 122-133. 
19. Khaloo AR and Kim N (1997) Influence of concrete and fiber characteristics on behavior of steel fiber reinforced concrete under direct shear, ACI Mater J, 94(6), 592-601.

20. Barragán B, Gettu R, Agulló L, Zerbino R (2006) Shear Failure of Steel Fiber-Reinforced Concrete Based on Push-off Tests, ACI Mater J, 103(4):251-257.

21. Lee GG, Foster SJ (2006) Behaviour of Steel Fibre Reinforced Mortar in Shear I: Direct Shear Testing, UNICIV Report No. R-444, The University of New South Wales, Sydney (Australia).

22. Cuenca E, Serna P (2010) Shear Behavior of Self-Compacting Concrete and Fiber-Reinforced Concrete Push-Off Specimens. In Proceedings of: Design, Production and Placement of SelfConsolidating Concrete, K.H. Khayat and D. Feys (eds.), RILEM Bookseries 1, 429. DOI: 10.1007/978-90-481-9664-7_36

23. Echegaray-Oviedo J, Navarro-Gregori J, Cuenca E, Serna P (2013) Upgrading the push-off test to study the mechanisms of shear transfer in FRC elements. In: Proc. VIII Int. Conf. on Fracture Mechanics of Concrete and Concrete Structures (FramCoS-8) (pp.1-10), J.G.M. Van Mier, G.Ruiz, C. Andrade, R.C. Yu and X.X. Zhang (Eds.), Toledo.

24. Jongvivatsakul P, Attachaiyawuth A, Pansuk W (2016) A crack-shear slip model of high-strength steel fiber-reinforced concrete based on a push-off test, Constr Build Mater, 126:924-935. 10.1016/j.conbuildmat.2016.09.080

25. ASTM Standard C143-15 (2015) Standard Test Method for Slump of Hydraulic-Cement Concrete, ASTM International, West Conshohocken, PA, 2015.

26. ASTM Standard C138-14 (2014) Standard Test Method for Density (Unity Weight), Yield and Air Content (Gravimetric) of Concrete, ASTM International, West Conshohocken, PA.

27. ASTM Standard C231-14 (2014) Standard Test Method for Air Content of Freshly Mixed Concrete by the Pressure Method, ASTM International, West Conshohocken, PA.

28. ASTM Standard C39 / C39M-05 (2005) Standard Test Method for Compressive Strength of Cylindrical Concrete Specimens, ASTM International, West Conshohocken, PA, 2005.

29. Garcia T, Blanco A, Cavalaro SHP (2016) Shear behaviour of sprayed concrete, Constr Build Mater, 124:722-731. doi: 10.1016/j.conbuildmat.2016.07.050

30. Cavalaro SHP, Aguado A (2015) Intrinsic scatter of FRC: an alternative philosophy to estimate characteristic values, Mater Struct, 48(11): 3537-3555. doi: 10.1617/s11527-014-0420-6.

31. Walraven JC (1981) Fundamental analysis of aggregate interlock, ASCE J Struct Div, 107(11):2245-2270.

32. Sherwood EG, Bentz EC, Collins MP (2007) Effect of Aggregate Size on Beam-Shear Strength of Thick Slabs, ACI Struct J, 104(2):180-190

33. Pujadas P, Blanco A, de la Fuente A, Aguado A (2012) Cracking behavior of FRC slabs with traditional reinforcement, Mater Struct, 45(5):707-725. doi: 10.1617/s11527-011-9791-0.

34. Blanco A, Pujadas P, de la Fuente A, Cavalaro SHP and Aguado A (2016) Influence of the type of fiber on the structural response and design of FRC slabs, Accepted in J Struct Eng-ASCE. doi: 10.1061/(ASCE)ST.1943-541X.0001515.

35. Buratti N, Mazzotti C and Savoia M (2011) Post-cracking behaviour of steel and macro-synthetic fibre-reinforced concretes, Constr Build Mater, 25(5):2713-2722. doi:10.1016/j.conbuildmat.2010.12.022.

36. Pujadas P, Blanco A, Cavalaro S and Aguado A (2014) Plastic fibres as the only reinforcement for flat suspended slabs: experimental investigation and numerical simulation, Constr Build Mater, 57:92-104. doi:10.1016/j.conbuildmat.2014.01.082.

37. Blanco A, Pujadas P, de la Fuente A, Cavalaro S and Aguado A (2014) Constitutive model for fibre reinforced concrete based on the Barcelona test, Cement Concrete Comp, 53:327-340. doi:10.1016/j.cemconcomp.2014.07.017.

38. Aire C, Carmona S, Aguado A and Molins C (2015) Double-Punch Test of Fiber-Reinforced Concrete: Effect of Specimen Origin and Size, ACI Mater J, 112(2):199-208. doi: $10.14359 / 51687362$.

39. Parmentier B, De Grove E, Vandewalle L and Van Rickstal F (2008) Dispersion of the mechanical properties of FRC investigated by different bending tests. In Walraven\&Stoelhost. fib Symposium "Tailor Made Concrete Structures". Amsterdam: Taylor \& Francis Group, p. 507-512 
40. Molins C, Aguado A and Saludes S (2009) Double Punch Test to control the energy dissipation in tension of FRC (Barcelona test), Mater Struct, 42(4): 415-425. doi: 10.1617/s11527-008-9391-9.

41. Pujadas P, Blanco A, Cavalaro SHP, de la Fuente A and Aguado A (2014) Multidirectional double punch test to assess the post-cracking behaviour and fibre orientation of FRC, Constr Build Mater, 58:214-224. doi: 10.1016/j.conbuildmat.2014.02.023. 